\title{
Special Issue in honor of John H. Kagel: Experimental Economics
}

\author{
(c) Economic Science Association 2021
}

(Coeditors: Andrzej Baranski (NYUAD), David Cooper (FSU), and Guillaume Frechette (NYU))

It is our great pleasure to announce a special issue in honor of John H. Kagel's path-breaking contributions to the field of experimental economics. We are soliciting submissions related to John's work on topics such as auctions, multilateral bargaining, communication, other-regarding preferences, strategic interactions between teams, cooperation, matching markets, and the role of context in strategic behavior.

John H. Kagel is currently the University Chaired Professor of Applied Economics and Director of the Economics Laboratory at the Ohio State University. Prior to joining Ohio State, John was Professor of Economics at the University of Pittsburgh. $\mathrm{He}$ is a fellow of the Econometric Society and has served as president of the ESA (2003-2005).

John's work over the last four decades has been published in the top journals across the social sciences and has contributed to the expansion and acceptance of the experimental methodology in economics, political science, and other social science disciplines. The academic community has benefited immensely from the clear organization and perspective that both volumes of the Handbook of Experimental Economics offer, which John coedited jointly with Al Roth.

The deadline for submission is October 31st, 2021 and our goal is to have the issue published in 2022. Please indicate in your cover letter that you are submitting for this special issue. All submitted papers will be refereed by the usual EE standards and procedures. Should you have any questions please email: kagelfest@ gmail. com. 